\title{
Los Torbado: el Patrimonio leonés y la evolución de la Restauración arquitectónica en España
}

\author{
Javier PÉREZ GIL \\ Universidad de Valladolid
}

Recibido: 3-10-2012 / Aceptado: 27-6-2013

RESUMEN: La Historia de la Restauración arquitectónica en el siglo XX en León tiene en los arquitectos Juan Crisóstomo Torbado Flórez y Juan Torbado Franco a dos de sus protagonistas más destacados. A través de su biografía y obra puede comprobarse tanto el distinto sesgo teórico de padre e hijo como la evolución que, en un contexto más amplio, experimentaron los criterios de Restauración, desde la lenta consolidación del conservacionismo en las primeras décadas de la centuria hasta la aparente vuelta a los planteamientos estilísticos.

Palabras clave: Restauración. Arquitectura. Patrimonio. León. Torbado Flórez. Torbado Franco.

ABSTRACT: Architects Juan Crisóstomo Torbado Flórez and Juan Torbado Franco are two prominent figures of twentieth century History of Architectural Conservation in León. Through their biographies and works it can be seen both various theoretical ideas between father and son, and, in a broader context, the Conservation's criteria evolution, from the slow consolidation of conservatism in early decades of the century until the apparent return to stylistic approaches.

Key words: Conservation. Architecture. Heritage. León. Torbado Flórez. Torbado Franco.

Las de Juan Crisóstomo Torbado Flórez y Juan Torbado Franco son dos de las figuras más representativas del panorama arquitectónico y cultural leonés del siglo $X X^{1}$. Durante casi ocho décadas fueron destacados protagonistas de su vida social, de su renovación arquitectónica y de la custodia de su Patrimonio construido. Pero además, representan de manera paradigmática una determinada evolución en el concepto

\footnotetext{
${ }^{1}$ Este artículo ha sido elaborado en el seno del Proyecto de Investigación “Juan Crisóstomo Torbado, Juan Torbado Flórez y su legado documental", financiado por la Junta de Castilla y León (VA091A08/2008-2010).
}

de Patrimonio -sus claves de acercamiento y criterios de intervención-, evolución que, acorde con el contexto coetáneo español, significará el abandono de un pensamiento teórico y operativo moderno y comprometido, y su súbita disolución en acciones inconexas y aparentemente ausentes de cualquier principio disciplinario. En este sentido, referida al ámbito de la Restauración arquitectónica, la biografía del padre se manifiesta mucho más interesente y profunda. El relevo de su hijo, por su parte, es consecuencia de las transformadas estructuras sociales del León de posguerra y está en sintonía con la relativa atonía de la Restauración española en 
materia teórica y de criterios, algo que padecerá en primera persona, a veces de manera irreparable, el Patrimonio de la provincia.

\section{JUAN CRISÓSTOMO TORBADO FLÓREZ}

\section{UN ESPÍRITU INQUIETO}

Juan Crisóstomo Torbado nació en Galleguillos de Campos (León) el 28 de enero de 1867 en el seno de una familia acomodada. Tras estudiar Arquitectura en Madrid, se instaló en la ciudad de León, donde pronto se incorporó a las obras de restauración de la catedral que por entonces se encontraba concluyendo Juan Bautista Lázaro. Sucedió a éste en el puesto y, además, acaparó otros importantes cargos que pronto le convirtieron en protagonista principal del panorama arquitectónico leonés, como los de arquitecto diocesano, provincial y municipal capitalino, este último ocupado de manera interina ${ }^{2}$. Desde estas responsabilidades tuvo oportunidad de participar de primera mano en buena parte de los proyectos edilicios provinciales, incluidos aquellos promovidos por la Diputación, los públicos de las localidades carentes de arquitecto municipal o los relacionados con las obras de la diócesis legionense.

Toda esta actividad institucional tuvo su paralelo en el ámbito profesional y cultural, síntoma inequívoco de la inquietud desbordante de una personalidad sumamente valiosa. Como profesional liberal, proyectó desde su estudio un buen número de obras que engalanan una carrera dilatada e igualmente interesante, principalmente

\footnotetext{
${ }^{2}$ Aunque Torbado, al que avalaba su experiencia y dos interinidades en el cargo, se presentó al concurso de provisión de la vacante de arquitecto municipal de León en 1900, tras un reñido y controvertido desempate, fue un recién licenciado, Manuel de Cárdenas, quien se hizo con la plaza (A.T. REGUERA RODRÍGUEZ, "Manuel de Cárdenas y los tres frentes del urbanismo leonés (1900-1925)", Los comienzos de una urbe emergente. Manuel de Cárdenas, arquitecto. León en los albores del siglo XX, COAL, 2003, pp. 58-67).
}

ligada a modelos eclécticos e historicistas -algunos con colaboradores de lujo, como Daniel Zuloaga ${ }^{3}$-, sin duda influidos por su formación madrileña, sus labores institucionales y su vasto conocimiento del Patrimonio histórico regional, pero que supo adaptarse a las nuevas demandas y materiales e, incluso, evolucionar hacia soluciones más modernas y renovadoras, como sus últimos proyectos en la zona del Ensanche ${ }^{4}$. Su labor fue, pues, valiosa en el ámbito de la profesión, pero también trascendente en la renovación y consolidación corporativa de la misma. Impulsó la fundación del Colegio de Arquitectos de Galicia, Asturias y León (1930) -en el cual ostentó el carnet de colegiado número 1-, y ocupó su presidencia y decanato desde el año de su creación hasta 1946, poco antes de su fallecimiento, cuando pasó a ser decano honorífico.

Esta labor en el ámbito profesional, fruto de un ánimo dinámico e incansable, era coherente con unos principios y valores que cultivó en su vida privada y que se traslucieron también en el ámbito público. Torbado fue un consumado dibujante. Su virtuosismo orientó inicialmente su vocación, le valió el reconocimiento en el taller de Lázaro y le permitió destacar también en el campo de la fotografía, que fue una de sus grandes pasiones. Otra de ellas fue el coleccionismo. Sus continuos viajes y sus discutibles prospecciones arqueológicas ${ }^{5}$ le permitieron hacerse

\footnotetext{
${ }^{3}$ M. VALDÉS FERNÁNDEZ, “Un aspecto del modernismo leonés: las cerámicas de Daniel Zuloaga", Estudios Humanísticos, nº 2, 1980, pp. 99-107.

${ }^{4}$ Véanse a este respecto los trabajos de M. SERRANO LASO, La Arquitectura en León entre el historicismo y el racionalismo 1875-1936, Universidad de León, 1993, y O. GARCÍA LUNA “Juan Crisóstomo Torbado", en: J.C. PONGA MAYO, El Ensanche de la ciudad de León 19001950, Colegio Oficial de Arquitectos de León, 1997, pp. 98-104.

5 BPL, Comisión Provincial de Monumentos, Libros de Actas. Torbado entregó algunas de las piezas de sus prospecciones a la Comisión Provincial de Monumentos, como las procedentes del yacimiento de Lancia, en 1916 -por las que recibió una gratificación de 8 pesetas-, o unos trozos de cerámica romana del pago de la Virgen
} 
con una magnífica colección que conocemos parcialmente a través de algunas piezas conservadas en archivos y museos, especialmente documentos, y de otras noticias recogidas de distintas fuentes. En 1929 cedió a su amigo Manuel Gómez Moreno varias para la exposición "El arte en España" que el segundo comisarió con motivo de la Exposición Internacional de Barcelona, entre ellas, un pendiente de oro, dos relieves románicos y una tabla hispanoflamenca del siglo $\mathrm{XV}^{6}$.

Torbado ya había participado con anterioridad en otras exposiciones, al socaire de las corrientes ilustradas y regionalistas que rezumaban las élites leonesas de principios de siglo. Fue uno de los impulsores y organizadores de la "memorable" exposición provincial de arte y antigüedades celebrada en 1906 en San Marcos de León, a la que contribuyó con varias piezas ${ }^{7}$. Ese mismo año participó igualmente en la creación de la Sociedad Leonesa de Excursiones, que tenía como objetivos organizar conferencias, viajes artísticos y fomentar el estudio y divulgación del Patrimonio histórico-artístico de la provincia ${ }^{8}$. En su junta directiva figuran nombres insignes de la vida cultural leonesa, como Eloy Díaz-Jiménez, Miguel Bravo y el arquitecto Manuel de Cárdenas. Torbado ostentó el cargo de director de excursiones, y el de presidente en 1908. Como responsable de las primeras, dirigió varias expediciones a monumentos de la capital y

(Sahagún), cedidos diez años más tarde. En 1930 donó dos chalecos típicos leoneses.

6 M. GÓMEZ MORENO, El arte en España. Guía del museo del Palacio Nacional, Barcelona, 1929, nํㅜ 783, 785, $787-790$, pp. $14,88,136,155,257$ y $286-287$.

7 Torbado presentó varias pinturas, muebles, bordados, miniaturas, adornos y otras obras artísticas (C. DE LUCAS DEL SER, “La Exposición monográfica de arte y antigüedades de 1906. Privacidad y manifestación pública del patrimonio de las élites leonesas", Tierras de León, no 124-125, 2007, pp. 51-70).

8 C. DE LUCAS DEL SER, Élites y Patrimonio en León, tesis doctoral, Universidad de Valladolid, 2007, pp. 355-363, y Élites y Patrimonio. La Comisión Provincial de Monumentos históricos y artísticos de León (1839-1991), Universidad de Valladolid, 2012. de la provincia, además de impartir conferencias y colaborar en la edición de la revista de la Sociedad, Literatura y Arte. El proyecto asociativo se mantuvo activo al menos hasta 1913. Poco después se fusionó con el Ateneo Científico y Literario Leonés, con el cual Torbado siguió colaborando?

La autoridad del arquitecto leonés en estas iniciativas venía avalada, además de por sus cargos, por su gran conocimiento de la Historia y Arte locales. Su contacto cotidiano con las obras del pasado le obligó a estudiarlas con rigor y detenimiento, divulgando algunas de sus investigaciones por medio de conferencias y publicaciones. Entre estas últimas se cuenta un libro, $\mathrm{La}$ catedral de León, opúsculo trilingüe que apareció en la colección "El arte en España", según algunos autores, hacia 1910 o 1915, y que nosotros dataríamos hacia $1926-1927^{10}$. Que tengamos noticia, colaboró también con la revista La Ilustración Española y Americana $(1901)^{11}$ y, especialmente, con el Archivo Espanol de Arte y Arqueología, donde publicó tres artículos: sobre el retablo de la capilla del Cristo de la Catedral de León (1931), el crucifijo del trascoro de la misma (1932) y el retablo procedente del convento de Santa María

\section{${ }^{9}$ C. DE LUCAS DEL SER, Ibidem.}

${ }^{10}$ J. TORBADO Y FLÓREZ, La catedral de León, Barcelona, H. de J. Thomas, s/f. El libro, como el resto de la colección, carece de data. No obstante, se publicó “bajo el patronato de la Comisaría Regia de Turismo y Cultura Artística", que dirigió el marqués de la Vega-Inclán desde su instauración, en 1911, hasta 1928. Torbado, p. 11, afirma que en ese momento, tras haber sido "aprobado por la Superioridad", se está procediendo al "picado, rejuntado y dorado de las bóvedas del claustro" y a la pavimentación del claustro, acción que puede observarse en una de las fotografías anejas. La primera acción debe corresponderse con la del proyecto presentado en 1910, si bien el encargo final del procedimiento de intervención de las pinturas no se verificó hasta 1918 (AHML, Fondo Torbado, caja 7925/2); la segunda, pudiera identificarse con un proyecto de 1926 (AHML, Fondo Torbado, caja 7929/8), que no quedó concluido hasta 1928.

11 J.C. TORBADO, "La Catedral de León en el siglo XV según una pintura de la época", La Ilustración Española y Americana, Madrid, noXXI, 1901, p. 352. 
la Real de Trianos, en la capilla de Jesús Nazareno de Sahagún (1936) ${ }^{12}$. En el primero de ellos aprovechó para dar noticia de su procedimiento en la recomposición del retablo, haciendo efectiva así la recomendación conservacionista de documentar las intervenciones, y en el segundo, que versaba sobre un tema sobre el que sin duda sentía un especial afecto por razones de procedencia, dejó testimonio de sus incursiones archivísticas, finalizando la redacción con una solicitud pública a los lectores de datos complementarios, o, en su defecto, la generosa oferta de los suyos para quien desease continuar con la pesquisa. De esta disposición colaboradora también quedaría constancia en el Catálogo Monumental de su amigo Gómez Moreno ${ }^{13}$.

\section{LA CATEDRAL DE LEÓN}

Torbado se inició en el mundo de la Restauración en la mejor escuela. Durante la segunda mitad del siglo XIX el de la catedral legionense había sido el gran proyecto de Restauración en España, la primera gran intervención tutelada por el Estado y lugar de encuentro de encendidos debates que reflejaron la instauración y maduración del debate disciplinario en nuestro país ${ }^{14}$. A la llegada

12 J.C. TORBADO, “Catedral de León. Retablo de la Capilla del Cristo", Archivo Español de Arte y Arqueología, no 21, 1931, pp. 213-219; "El Crucifijo del trascoro de la Catedral de León", Archivo Español de Arte y Arqueología, no 22, 1932, pp. 49-54; "El retablo de Trianos y los relieves de Sahagún", Archivo Español de Arte y Arqueología, no 34, 1936, pp. 76-85.

13 M. GÓMEZ MORENO, Catálogo monumental de España. Provincia de León, t. I, Madrid, 1925. Aunque su colaboración fue estrecha y su afecto público y recíproco, el epistolario del granadino revela ciertas cautelas hacia el leonés. En 1931 prevenía a Alejandro Ferrant sobre la participación de Torbado en la restauración de la iglesia San Miguel de Escalada en los siguientes términos: “...como ello viene por conducto de la Comisión de Monumentos, y allí mangonea Torbado, que tiene empeño en mangonearlo todo..." (J.E. CHAPAPRÍA y Ma.P. GARCÍA CUETOS, Alejandro Ferrant y la conservación monumental en España (1929-1939), Junta de Castilla y León, t. I, 2007, p. 232).

${ }^{14}$ La bibliografía sobre este proceso es extensa y de Torbado dirigía las obras Juan Bautista Lázaro, que había sustituido al violletiano Demetrio de los Ríos, fallecido en 1892. Este cambio supuso un giro en los criterios de Restauración, al abandonarse el fundamentalismo estilístico, para entonces ya abiertamente criticado desde numerosos frentes, en beneficio de una postura, si no antirrestauradora, sí más conservacionista y cercana a la mínima intervención boitiana, como demuestra la paralización del proyecto de traslado del coro, impulsado enérgicamente por De los Ríos y al que el nuevo arquitecto se opuso desde un principio. Además de su amplio currículum como restaurador en distintos monumentos españoles, Lázaro teorizó sobre los criterios de intervención y sobre la disciplina misma, y no cabe duda de que sus posiciones debieron calar en el joven Torbado.

Éste se incorporó al equipo de la catedral en 1893. En aquellos primeros años, su labor se centró principalmente en el proyecto de recuperación de las vidrieras, para las que preparó multitud de dibujos. El buen trabajo realizado al servicio de Lázaro le valió el cargo de arquitecto auxiliar y, tras el abandono del primero, el de director de las obras, según señalaba él mismo con humildad, "sin otro mérito por nuestra parte, que el haber desempeñado durante quince años el cargo de arquitecto auxiliar de las mismas"15. Concluidos los trabajos de restauración tras medio siglo de intensa actividad, su ocupación al frente de las obras se centró principalmente en "proyectos de conservación", aunque no estuvo exenta de algunos conflictos, nuevos, aunque heredados del pasado.

Entre ellos destaca sin duda el proyecto de liberación de las edificaciones anejas al costado meridional de la catedral, que pretendía dar continuidad a las tesis

cuenta con excelentes estudios, como los de I. GONZÁLEZ-VARAS IBÁÑEZ, La catedral de León. Historia y Restauración (1859-1901), Universidad de León, 1993, y La catedral de León. El Sueño de la Razón, Cabildo de la Catedral de León, 2001.

15 J. TORBADO Y FLÓREZ, La catedral, p. 11. 
estilísticas de De los Ríos para dejar el templo libre y exento de cualquier continuidad añadida, como un objeto escultórico, acabado en su concepción estética e idealista y ajeno a su entorno. Junto a estos fines cabe añadir también, como ha señalado Carmelo de Lucas, el interés personal de determinadas élites sociales, especialmente de Fernando Merino, por eliminar estas barreras viarias y favorecer así la expansión de la ciudad hacia oriente, donde éste tenía establecimientos industriales ${ }^{16}$. Fue precisamente Merino quien solicitó en 1906 la demolición al ministro de Instrucción Pública, y quien volvió a hacerlo en 1910, entonces como ministro de la Gobernación. En esta ocasión, con el apoyo de todo el engranaje merinista, así como con el beneplácito del obispado y la pasividad de los organismos de control, el proyecto fue aprobado, pasándose a derribar, por vía de urgencia, parte de la muralla, el antiguo provisorato eclesiástico y las galerías de Puerta Obispo, que comunicaban con el palacio episcopal. Con su ejecución se liquidaba parte del Patrimonio capitalino y se dejaba a su catedral herida y descarnada de una parcela de su historia.

Entre los opositores a esta destrucción, que veían en las obras amenazadas un mérito histórico y artístico, se señalaron algunas figuras destacadas, como la de Manuel Gómez Moreno o la de parte de la Comisión Provincial de Monumentos, entre la que se encontraba Torbado, que se mantuvo fiel a sus principios conservacionis$\operatorname{tas}^{17}$ a pesar de las presiones. No obstante, ese posicionamiento le costó la dirección de las obras, siendo relevado en agosto de 1910, con el beneplácito de Merino, por el arquitecto Manuel de Cárdenas (1911-1913), quien se encargó de los derribos. En este

\footnotetext{
${ }^{16}$ C. DE LUCAS DEL SER, Élites, pp. 740-753.

17 Juan Bautista Lázaro ya se había opuesto abiertamente en 1884 y 1886 a este tipo de eliminaciones, pretendidas por Demetrio de los Ríos (L. TORRES BALBÁS, "El aislamiento de nuestras catedrales", Arquitectura, 1919, en Sobre monumentos y otros escritos, COAM, 1996, pp. 37-41).
}

sentido, la firmeza que demostró Torbado en un contexto ciertamente delicado, aunque recibiese el continuo apoyo de Gómez Moreno, refuerza el valor de sus convicciones, coherentes con el liderazgo de unas responsabilidades en las que debía primar la voluntad de desarrollo de unos objetivos profesionales sobre cualquier otro tipo de interés o beneficio material. De hecho, sus honorarios como director de obra en la catedral no debían ser una razón de peso para asumir las obligaciones que conllevaba. En 1914, de vuelta a la rutina en el cargo, Ricardo Velázquez Bosco explicaba a Gumersindo de Azcárate que Torbado no tenía asignado ningún sueldo por su trabajo en la catedral, pues desde que se hubo aprobado la nueva tarifa de honorarios, que pasaban a fijarse en función del importe de cada obra, no se había vuelto a nombrar ningún arquitecto con sueldo. Su razonamiento podría seguir siendo válido hoy para bastantes arquitectos restauradores:

“La restauración de monumentos son
cargos casi honoríficos y de confianza
y la mayor parte no cobramos nada
o casi nada por ello porque como la
cantidad que se gasta a esas obras es
muy pequeña los honorarios corres-
pondientes son muy escasos y ése es
el caso de Torbado a pesar de que su
asiento en las obras de restauración
que tiene a su cargo son bien notorio,
y esa es la única satisfacción que se
saca de esa clase de obras, pues real-
mente a la conservación de los monu-
mentos venimos todos obligados"18

Las estrecheces pecuniarias que motivaban las precauciones hacia el cargo de arquitecto de la catedral afectaron también a las obras, cuyos presupuestos salieron a menudo adelante gracias a las gestiones del propio Torbado, a través de contactos bien situados como el de su sobrino Pablo

${ }^{18}$ Carta de Ricardo Velázquez a Gumersindo de Azcárate, 5 de junio de 1914 (AHML, Fondo Torbado, caja 7915/9). 
de Azcárate Flórez, diputado en Cortes por León ${ }^{19}$. Como dijimos, bajo su dirección se trató principalmente de proyectos de conservación y mantenimiento, proyectos que, además de presentarse en el contexto económico citado y posterior a la clausura de los grandes trabajos de restauración, concordaban con los criterios de la Escuela anti-restauradora: reparaciones de cubiertas y consolidaciones varias $(1918)^{20}$, reparaciones, limpiezas y protección de vidrieras $(1920,1921)^{21}$, o trabajos de saneamiento como el desagüe y pavimentación del claustro (1926) ${ }^{22}$ (Fig.1). En la memoria de este último proyecto, Torbado volvió a reiterar su aspiración de ver algún día fundado un museo en el que se expondrían piezas como las que había ido almacenando provisionalmente en el claustro, "siempre con la idea de poder algún día colocarles de una manera definitiva para su mejor conservación y siendo la base de un principio de Museo que creemos se debe formar con todos los restos interesantes procedentes de las distintas obras que en épocas diferentes se han llevado a cabo en este notable Monumento" ${ }^{23}$. Esta propuesta refleja la visión que tenía, no sólo de la catedral como resultado de contribuciones de distintas épocas -superando el periodo gótico-, sino también de la sucesión de restauraciones, de las que él mismo había formado parte, como un proceso caducado y que era asimismo parte de su historia. Está, además, en la línea de documentación y divulgación de las modernas corrientes restauradoras que circulaban entonces por Europa.

\footnotetext{
${ }^{19}$ AHML, Fondo Torbado, caja 7915/9.

${ }^{20}$ AHML, Fondo Torbado, caja 7929/5.

${ }^{21}$ AHML, Fondo Torbado, cajas 7929/6 y 7929/7.

22 Para la relación de otros proyectos entre 1930 y 1944, véase I. GONZÁLEZ-VARAS IBÁÑEZ, La catedral de León, p. 499; Ma.A. ROBLES ROBLES, “Intervenciones en las vidrieras de la Catedral de León en el siglo XX", En torno a la catedral de León (estudios) (J. PANIAGUA y F.F. RAMOS, coord.), Universidad de León,2004, pp. 399-409.

${ }^{23}$ AHML, Fondo Torbado, caja 7929/8.
}

De entre todas sus intervenciones en la catedral queremos destacar dos por lo que tienen -si se nos permite la expresión- de intervención directa de restauración. La primera es su trabajo de recomposición y diseño de retablos. Ayudó a Lázaro a rehacer el de Nicolás Francés (1900-1907), que había sido retirado de la capilla mayor en 1740 para sustituirse por otro barroco, el cual Demetrio de los Ríos había desmontado sin llegar a reemplazarlo. En 1901, reabierto el culto en la catedral, la necesidad de un retablo mayor digno era perentoria, y fue entonces cuando el hallazgo de unas noticias documentales sobre su paradero propiciaron su búsqueda y recuperación ${ }^{24}$. Siguiendo las pistas, Torbado localizó varias tablas originales en las parroquias de La Aldea de la Valdoncina y Trobajo del Camino, a donde habían llegado como donación en 1741. A éstas sumó otras piezas tardogóticas de diferentes lugares de la diócesis y, con todas ellas, procedió a su restauración y recomposición (Fig.2), contando para su limpieza y retoque con la ayuda de los pintores Primitivo Álvarez Armesto y Gerardo Meléndez ${ }^{25}$.

Dado que ni se localizaron todas las piezas originales ni se conocía su disposición exacta, el retablo resultante respondió a una nueva figuración ${ }^{26}$. Eloy Díaz Jiménez, que también colaboró en el proceso, lo califica de "reconstrucción". Sus juicios y preferencias parecen seguir criterios estilísticos, acusando la obstrucción que generaba para la libre contemplación de la girola ${ }^{27}$, aunque

24 J.E. DÍAZ JIMÉNEZ, Catedral de León. El retablo, Madrid, 1907.

${ }^{25}$ J.E. DÍAZ JIMÉNEZ, Op. cit, p. 45.

${ }^{26}$ Mientras que el resultante responde a una composición vertical, A. FRANCO MATA, "Pintura medieval o el genio de Nicolás Francés", La catedral de León. Mil años de Historia, León, Edilesa, 2002, pp. 152-167, considera que el original debió ser una obra de superior formato, de $13 \mathrm{~m}$. de ancho por 6 de altura. Aporta igualmente una hipótesis de cómo sería éste, con todas sus tablas.

${ }^{27}$ En este sentido, también se lamenta de la frustración del proyecto de traslado del coro al presbiterio, 
justificando el resultado final por su mimético parecido con lo original:

“...se ha procedido a ejecutarla (la obra) con tanta inteligencia y profunda intuición de lo antiguo, que es muy difícil distinguir, a la primera ojeada, lo nuevo de lo viejo. La pureza de las líneas, la uniformidad de los tonos y la armonía del conjunto son de tal naturaleza, que parécenos tener ante nuestros ojos uno de aquellos grandiosos altares que en el siglo XV enriquecían los ábsides de nuestros templos" 28

No creemos, sin embargo, que Lázaro y Torbado entendiesen esta intervención según tales principios decorativos, como labor culminante de un proyecto integral de Restauración en estilo a partir de la introducción de mobiliario neogótico dirigido a la perfección de una idea artística rectora. Consideramos, más bien, que la aparición fortuita de algunas piezas originales del siglo XV se les presentó como una oportunidad para recuperarlas y solucionar una de las carencias funcionales -litúrgica, en este caso- de un edificio que volvía a estar vivo, oportunidad que, además, estaba favorecida por el previo desmonte del retablo del XVIII. Quizás en correspondencia con esta interpretación estén las justificaciones que acompaña el propio Díaz-Jiménez, seguramente recogidas de los arquitectos responsables, al propugnar cierto respeto también hacia los añadidos de diferentes épocas incorporados a la arquitectura $^{29}$. La composición del retablo, efectivamente, contó con otras piezas históricas de diferente origen, además de recogerse en un

que hubiera querido Demetrio de los Ríos, y que Lázaro impidió (J.E. DÍAZ JIMÉNEZ, Op. cit., p. 9).

${ }^{28}$ J.E. DÍAZ JIMÉNEZ, Op. cit., p. 7.

29 "Es evidente que, para el buen restaurador, no debe merecer respeto aquello que desnaturalice el carácter del monumento y sacrifique su unidad, forma y estilo primitivo, tanto más si contribuye a poner en peligro su existencia; pero sí entendemos que es digno de respeto cuanto, no oponiéndose a esta ley fundamental, han ido agregando las generaciones sucesivas" (J.E. DÍAZ JIMÉNEZ, Op. cit., p. 8). marco neogótico, pero esta solución, con la indiferencia hacia la notoriedad visual que llevaba implícita, es la nueva figuración aportada por sus diseñadores. Unos años antes, el propio Camillo Boito había procedido de manera análoga, y quizás más discutible, con el altar de Donatello en la basílica de San Antonio de Padua, aplicando, más que una reconstrucción, un principio "imitativo" 30 .

A esta intervención se sumó la del retablo de la capilla del Cristo (1931), obra de Juan de Valmaseda, que Torbado documentó en un artículo ${ }^{31}$. En este caso, la recomposición fue menos imaginativa, por contar con casi todas las piezas y formar parte de una unidad más sencilla, aunque tampoco fue tarea fácil. Tomando como referencia las únicas piezas que se encontraban in situ -el grupo del calvario-, buscó y localizó el resto en lugares bien variopintos: "los cuatro Evangelistas, fácilmente pudieron ser reconocidos, aunque cada uno ocupaba muy diferente sitio; pero los elementos arquitectónicos y decorativos fueron a parar, unos, a la trastera; otros, tuvimos la suerte de salvarlos del fuego que se hacía en las obras, para calentar el agua, y algunos se encontraron en las bóvedas, sin explicarnos aún cómo fueron a parar a semejante sitio". Con todas las partes reunidas, recompuso el retablo "sin haber necesitado torturar la imaginación con invenciones más o menos acertadas, de las que ha de huír todo restaurador discreto" (Fig.3).

El segundo proyecto al que nos referíamos, interesante para analizar los criterios y metodología de Torbado, es el de "reparación de pinturas murales y bóvedas del claustro" $^{32}$, de 1910 (Fig.4). Estas pinturas, obra de Nicolás Francés y otros artistas, habían despertado con anterioridad el interés y preocupación de Demetrio de los Ríos,

30 F. CASTELLANI, Camillo Boito. Un'archittetrura per l'Italia unita, Venecia, Marsilio, 2000, pp. 128-132.

31 J.C. TORBADO, “Catedral de León. Retablo de la Capilla del Cristo", Op. cit.

${ }^{32}$ AHML, Fondo Torbado, caja 7925/2, Op. cit. 
quien deseaba verlas algún día restauradas en clave estilística o, mejor dicho, storicis$t a$, con sus líneas reforzadas y sus colores recuperados "con paciencia y fidelidad sumas..., sin adición alguna" ${ }^{\prime 3}$. No obstante, la magnitud de la obra, y la "moderna preocupación de abandonar los monumentos fatalmente a sí mismos", le persuadían de ver satisfecho ese deseo.

Fue precisamente uno de esos modernos conservadores, Torbado, quien planteó años más tarde la restauración de las pinturas: “No se nos oculta el peligro que se corre al poner mano en obras tan delicadas, pero como sustentamos la teoría de conservarlas, hoy nos atrevemos a proponer su reparación, no para restaurarlas, sino para sacarles a luz, y principalmente con el fin de evitar su completa desaparición, lo que sería, sin disputa, una irreparable pérdida por todos los conceptos". Con esa "reparación" Torbado se estaba refiriendo a unos trabajos de consolidación y limpieza. Para la primera proponía contener la fragmentación que afectaba a la película pictórica, sin tocarla, recogiendo sus bordes en un encintado de mortero de cemento y arena. Una vez asegurados éstos, se procedería a eliminar la pátina que impedía la visión de la obra por medio de un lavado, al que seguiría un barnizado. Para comprobar la efectividad de su procedimiento, Torbado lo aplicó, a modo de ensayo y con demasiado atrevimiento, sobre algunos sectores de las pinturas del claustro y del interior de la catedral. En la limpieza empleó materiales y técnicas que consideró inocuos -"agua limpia, transmitida con algodón o esponja fina"-, a fin de retirar la pátina sin alcanzar la película pictórica. Eliminada dicha pátina, a la que consideraba sólo en su condición de suciedad, quizás por tratarse de una obra pictórica, se aplicó, por medio de un pulverizador, una "finísima capa de barniz especial".

Los experimentos sacaron a la luz nuevas figuras y repintes, ante los cuales

33 D. DE LOS RÍOS Y SERRANO, La Catedral de León, t. I, Madrid, 1895, pp. 129-130.
Torbado partía de un principio de respeto a cualquier tipo de añadido: "nuestro propósito no es intentar la desaparición de esos repintados posteriores, pues además de ser empresa difícil y peligrosa por estar ejecutados con óleo unos y otros al temple, creemos, por el contrario, que deben ponerse de manifiesto para su estudio y comparación, porque, entre otras razones, es uno de los medios más prácticos y sencillos de llegar al conocimiento completo del arte pictórico". Permitieron asimismo contemplar las composiciones antes ocultas bajo el ennegrecido de la pátina. Estos resultados le llevaron a considerar acertado el procedimiento y magníficas las expectativas de la restauración en cuanto a resultados.

La Academia de Bellas Artes, sin embargo, no tuvo la misma opinión. Encargó una valoración al académico de su sección de Pintura José Garnelo, quien hizo público su informe el 23 de octubre de 1917. Como Torbado, coincidía en reconocer el valor de las pinturas, aunque no en la forma de actuar sobre ellas. Para la limpieza, al tratarse de temples, desaconsejaba totalmente el empleo de agua, y, para el fijado, cualquier tipo de barniz con líquidos resinosos de laca o goma, aunque fuesen pulverizados. Estas conclusiones supusieron un duro revés para Torbado, especialmente por poner en evidencia sus criterios y procedimientos, con la reiteración académica de la necesidad de "un manejo profesional" y otras críticas que parecen aplicarse sobre algunos ensayos no recogidos en la memoria. En efecto, Garnelo cita el repintado de algunas figuras -"retoque o avivado de los contornos con tinta negra como se ha hecho con los ya restaurados"-, al parecer, en la línea de lo propuesto por De los Ríos, y que criticaba por lo que suponían de falsificación para el trazo del artista, que el restaurador intentaba suplantar, y para el entendimiento de la propia pintura, al potenciar discrecionalmente el dibujo sobre el color. En su opinión, debía procederse a "la conservación íntegra de dichas pinturas tal como se encuentran por indeterminadas y borrosas que estén". 
La Academia confirmó estas conclusiones, aprobando en 1918 la restauración, aunque con los nuevos criterios.

Torbado, aunque finalmente vio satisfecho su deseo de recuperar las pinturas, vio desautorizados sus planteamientos, que dejaron en evidencia las lagunas de su posición conservadora, al menos en su sentido más integrista ${ }^{34}$. En otra de las propuestas de ese proyecto de 1910, el "picado, rejuntado y dorado de las bóvedas del claustro", se mostró partidario de eliminar algunos añadidos con el fin de poner en valor partes que consideraba más importantes (Fig.5). Se trataba de los revoques de las bóvedas de la crujía meridional del claustro, que ocultaban a la vista del espectador "no sólo el sistema seguido para su construcción, haciendo invisible su verdadero despiezo, sino también (lo que es aún más sensible) impide con esos torpes añadidos, admirar los hermosos relieves tallados en piedra". Por esta razón, aprovechando la presencia de andamios "e inspirados en el sistema de restauración constantemente seguido en este monumento", que, además de dar continuidad a los seculares procedimientos estilísticos, había permitido contar con una plantilla de obreros diestros en esas labores, proponía eliminar los revoques a fin de rescatar la configuración primigenia. Como hiciera con la intervención inicial de Torbado en las pinturas murales, Gómez Moreno también criticó ésta, entre otras razones, porque su ensayo en la restitución de la policromía de las filacterias, además de desentonar gravemente, podría

34 También M. GÓMEZ MORENO, Catálogo, pp. 271-272, que mantenía una cordial relación con Torbado, criticó la restauración de éste, especialmente la eliminación de los retoques modernos y el perfilado de contornos, aunque intentase suavizar su valoración reconociendo la acreditada trayectoria del leonés como restaurador. Las últimas restauraciones de las pinturas (1994-1997) han optado por mantener los retoques de Torbado por su carácter irreversible y considerarlos ya parte de la historia del conjunto (P.L. YAGÜE HOYAL, "Historia de la restauración de las pinturas murales del claustro de la catedral de León", Restauración de las pinturas murales del claustro de la catedral de León, Junta de Castilla y León, 1997, pp. 59-67). animar algún día a completar el repinte del resto, "provocando una invalidación de lo antiguo, absurda e irremediable" ${ }^{\prime 35}$. Respecto a la eliminación de revoques, no obstante, consideramos que no ha de entenderse necesariamente en términos estilísticos, a pesar de primar la instancia estética sobre la documental, pues también está en consonancia con actitudes modernas e incluso críticas.

La limitada extensión de este trabajo nos impide referirnos a otras obras de Torbado, como su intervención en la colegiata de San Isidoro de León o las que realizó en distintos monumentos leoneses, religiosos y civiles, en ocasiones incorporando nuevas construcciones -generalmente con líneas ecléctico-historicistas como el campanario neorrománico que diseñó para la iglesia de Pedrosa del Rey $(1898)^{36}$, en la línea de otros proyectos de obra nueva (iglesia de San José de las Ventas, León, 1928)-, a veces con líneas algo más depuradas, como las del cuerpo central del palacio de Villasinda en León (1907-1908), donde introdujo la notoriedad visual aunque alterando la configuración volumétrica del edificio histórico ${ }^{37}$.

Sus posiciones acerca del Patrimonio y su conservación pueden también

${ }^{35}$ M. GÓMEZ MORENO, Catálogo, pp. 273-274.

${ }^{36}$ AHML, Fondo Torbado, caja 7903/3.

${ }^{37}$ M ${ }^{a}$.D. CAMPOS SÁNCHEZ-BORDONA y Mª.L. PEREIRAS FERNÁNDEZ, "Aportaciones a la Arquitectura señorial leonesa. Nuevos datos sobre el palacio de Villasinda", Estudios Humanísticos, no 21, 1999, pp. 236-262; E. MORAIS VALLEJO y Ma D. CAMPOS SÁNCHEZ-BORDONA, Edificios civiles de la ciudad de León en la Edad Moderna, Universidad de León, 2007, pp. 205-221. En la iglesia de Santa María del Mercado (León), procedió a la práctica reconstrucción del ábside del Evangelio, si bien simplificando algunos elementos como capiteles (Fig.6). Fruto de ese interés por diferenciar las partes nuevas es también la firma de su ayudante en una de las basas del vano central: "Julio del Campo, Aydte. de J. C. Torbado" (J.M. RODRÍGUEZ MONTAÑÉS, Enciclopedia del Románico en Castilla y León, t. León, Fundación Santa María la Real, 2002, pp. 571-572). 
analizarse a través de su presencia en la Comisión Provincial de Monumentos, con independencia del escaso papel operativo y decisorio que tuvieron estos comités. Torbado ingresó como vocal del leonés en 1910, tras haber sido propuesto sin éxito en $1905^{38}$. Era entonces director de obras de la catedral y restaurador de San Isidoro, y su currículum le llevó a participar de manera activa desde un principio en los debates y actividades de la Comisión, empezando, en ese mismo año, por la citada y polémica propuesta de liberación de la catedral, a la que se opuso, aconsejando la previa valoración de las estructuras por especialistas reconocidos ${ }^{39}$.

A lo largo de su dilatada estancia en la Comisión ocupó diversos cargos: de 1910 a 1936 el de vocal, y conservador artístico desde 1919, cuando entró en vigor el nuevo reglamento que suplía al anticuado de $1865^{40}$, llegando incluso a presidir la sesión ordinaria en 1929 por ausencia del presidente y ser el académico más antiguo ${ }^{41}$. Tras la Guerra Civil, se reincorporó a la renovada Comisión hasta su fallecimiento en 1947, si bien la presencia familiar tuvo su continuidad a través de su hijo Juan, en un claro y frecuente ejemplo de patrimonialización de puestos en este tipo de organismos. Durante todos estos años, elaboró numerosos informes técnicos sobre edificios de toda la provincia. Su participación fue destacada en los debates, planteando con firmeza sus denuncias ante derribos como el citado de la catedral o los de las iglesias mudéjares coyantinas, o la polémica venta irregular de bienes artísticos en la diócesis de Astorga (1929) ${ }^{42}$. Una actitud,

38 BPL, Comisión Provincial de Monumentos, Libros de Actas, ff. 45r-46r, 60r-61v, 65rv.

39 BPL, Comisión Provincial de Monumentos, Libros de Actas, 3 de agosto de 1910.

${ }^{40} \mathrm{RD}$ de 11 de agosto de 1918, Reglamento de las Comisiones provinciales de Monumentos históricos y artísticos. Véase también C. DE LUCAS DEL SER, Op. cit.

${ }^{41}$ BPL, Comisión Provincial de Monumentos, Libros de Actas, ff. 21v-22v.

42 BPL, Comisión Provincial de Monumentos, Libros pues, comprometida y responsable con las atribuciones de la Comisión, aunque quizás también con algún punto oscuro, como parece evidenciar su silencio en 1931 ante el caso de venta de varias piezas del monasterio de San Pedro de las Dueñas -localidad vecina de su Galleguillos natal-, al parecer, sin la presencia del arquitecto diocesano, a la sazón el propio Torbado ${ }^{43}$.

Como conclusiones generales, Juan Crisóstomo Torbado representa la consolidación de las teorías conservadoras o antirestauradoras en el contexto del Patrimonio leonés. Entiende los monumentos desde una perspectiva moderna, totalmente desligada de los criterios estilísticos decimonónicos, y con una mayor valoración de la conservación como principio. Su trabajo se mantuvo básicamente fiel a estas premisas, mostrándose firme ante situaciones comprometidas y presiones políticas, y asumiendo sus consecuencias. Esta coherencia en sus planteamientos y proyectos, además de evidenciar su categoría como restaurador (con independencia de su adscripción teórica), también se manifestó en otros aspectos de su vida profesional, pública y privada. Su figura, pues, es una de las descollantes en el ya de por sí rico panorama cultural de las primeras décadas del siglo XX en León.

\section{JUAN TORBADO FRANCO}

Juan Torbado Franco no heredó de su padre las mismas inquietudes hacia el Patrimonio. Nacido en León el 25 de agosto de 1901, su formación y desarrollo como arquitecto poco tuvieron que ver con el contexto de su progenitor, natural continuador de un siglo XIX marcado por el protagonismo de la Historia y el magno proyecto de restauración de la catedral de León, con sus encendidos

de Actas, ff. 25v-28v; L.A. LUENGO, R. GULLÓN y L. PANERO, Guía de Astorga, Astorga, 1929, pp. 42 y 74.

43 BPL, Comisión Provincial de Monumentos, Libros de Actas, ff. $42 \mathrm{v}-44 \mathrm{v}$. 
debates. Torbado Franco ejemplifica la figura de uno de tantos arquitectos que tuvieron que enfrentarse a un mundo nuevo, a los radicales cambios de las tendencias arquitectónicas que buscaban superar el tradicionalismo vigente, $\mathrm{y}$ al declive de la preocupación por la teoría de la Restauración, motivado por la Guerra Civil y el consiguiente periodo de posguerra bajo el régimen franquista.

Tras estudiar en el colegio de los agustinos de León, cursó Arquitectura en la Escuela de Madrid y completó su formación en varios países europeos, como Inglaterra o Alemania, donde se benefició de una beca del Estado español para estudiar sobre la catedral de Colonia el problema de la conservación y protección de la piedra ${ }^{44}$, sin duda, con vistas a su posible aplicación en la legionense. Como su padre, y en ocasiones gracias a su influencia, ostentó numerosos cargos y distinciones a lo largo de su vida, entre ellos, su nombramiento como miembro correspondiente de la Academia de Bellas Artes de San Fernando, la dirección de las obras de la Catedral, el cargo de arquitecto diocesano de León o su puesto en la Comisión Provincial de Monumentos.

Todas estas responsabilidades le ligaron al mundo del Patrimonio, aunque su actividad más notoria como arquitecto la realizó desde su estudio profesional, en proyectos de obra nueva para instituciones públicas y clientes particulares de toda la provincia y su área de influencia. La Escuela de Comercio de León, la Maternidad, las viviendas de Oficiales y Jefes del Ejército del Aire o el edificio de 15 plantas en la calle dedicada a su padre, son algunas de las obras que jalonaron su fecunda actividad hasta su muerte en 1971. Juan Carlos Ponga ha clasificado toda esta producción en tres etapas $^{45}$. La primera, que recoge sus prime-

${ }^{44}$ J.Ma. FERNÁNDEZ CATÓN, “In memoriam Don Juan Torbado Franco", Archivos Leoneses, no 50, 1971, pp. 383-384.

45 J.C. PONGA MAYO, El Ensanche de la ciudad de León 1900-1950, Colegio Oficial de Arquitectos de León, ros proyectos hasta 1933, estaría presidida por su intervención en el Pabellón Antituberculoso del Instituto de Higiene (1932), proyecto renovador de un joven y moderno arquitecto, en el que se acercó a los esquemas racionalistas ya ensayados por Ignacio de Cárdenas y José María de Vega en el edificio de la Telefónica (1931) de la calle del Padre Isla, recientemente amputado por un salvaje vaciado operado en sintonía con las prácticas de fachadismo que, en pleno siglo XXI, siguen permitiéndose sobre el Patrimonio de la capital leonesa. Una segunda etapa es la que compartió en compañía del arquitecto Ramón Cañas del Río (1933-1944), marcada por el hemistiquio de la Guerra Civil, donde erigieron primero expresivos edificios de viviendas en ladrillo visto entre potentes cuerpos, para simplificar, después, los volúmenes y aumentar la carga ornamental e historicista. Esta tendencia tendría su continuidad en sus últimas décadas de actividad, desde 1945, en las que acomodó sus diseños a la demanda tradicional, aunque intercalase también proyectos de otro sesgo ${ }^{46}$.

No es, sin embargo, su obra construida la que nos interesa ahora, sino la relacionada con el Patrimonio y la Restauración. De esta última, nos centraremos en algunos aspectos y obras de las muchas que realizó en edificios de la capital y su diócesis con ocasión de su cargo de arquitecto diocesano.

\section{LOS AÑOS PERDIDOS}

La Restauración como disciplina, y su debate, irrumpieron y se consolidaron en España en las décadas centrales del siglo XIX, una vez que las instituciones hubieron tomado conciencia del valor público de los monumentos y sus necesidades. Se impusieron entonces las teorías estilísticas importadas de Francia, con tal fuerza, que

1997, p. 146.

${ }^{46}$ AHML, Fondo Torbado. 
mantuvieron su hegemonía hasta entrado el siglo XX, cuando las voces discrepantes surgidas en el contexto teórico de la nueva valoración del monumento consiguieron desacreditar definitivamente la Restauración en estilo por falsaria y perniciosa para el documento histórico. En este proceso se dilató un apasionante y productivo debate entre la denominada Escuela restauradora y la conservadora -o "anti-rrestauradora", en términos tendenciosos de uno de sus opositores ${ }^{47}$-, debate que demuestra la altura formativa y teórica de ambas partes, en el que participaron figuras de la talla de Demetrio de los Ríos, Vicente Lampérez o Leopoldo Torres Balbás.

Las posiciones conservadoras, que participaban también de las corrientes revisionistas que se extendían entonces por Europa, finalmente se impusieron, aplicándose con distinta fortuna, aunque con convicción, en el periodo de la II República. España se convirtió en una de las abanderadas de estas teorías en Europa, pero el estallido de la Guerra Civil dio al traste con la aplicación efectiva de sus postulados. Tras la contienda, sobre el solar de un país desolado y pleno de calamidades y necesidades perentorias, las preocupaciones sobre la tutela conservacionista de los monumentos pasaron a un lugar secundario. Es más, acabaron por difuminarse por completo, $\mathrm{y}$, cuando la Dictadura pudo restablecer el control y cuidado de su Patrimonio, se tendió a recuperar el guión de la Restauración en estilo, aunque ahora con un carácter estrictamente monumentalista y escenográfico, exento de la potencia y trascendencia teórica que había tenido en el pasado. Es en este contexto en el que Juan Torbado desempeñó su actividad, con criterios variables y que no siempre atendían a la especificidad de los edificios en tanto que Patrimonio, evidenciando, con ello, su falta de atención o compromiso teórico.

\footnotetext{
${ }^{47}$ V. LAMPÉREZ Y ROMEA, La Restauración de los monumentos arquitectónicos. Teorías y aplicaciones, Madrid, Asociación Española para el progreso de las Ciencias, 1913.
}

Como arquitecto diocesano, trabajó en multitud de pequeñas iglesias, generalmente con motivo del mal estado de algunas de sus partes. La norma habitual fue en estos casos la reconstrucción, a veces por medio de formas predominantemente modernas -caso de las iglesias de Litos (1958), Valsemana (1959), Genicera (1963) o Vega de Infanzones $(1966)^{48}$-, otras según repertorios eclecticistas, como las de La Mata de Monteagudo (1953), Quintanilla de Rueda (1954), o su proyecto para la capitalina parroquia de San Pedro de los Huertos (1964) ${ }^{49}$. Sin embargo, en la adopción de una u otra postura no parece subyacer ningún criterio en relación a las preexistencias. Las memorias de sus proyectos no prestan ninguna atención al valor histórico o artístico, y sus resultados parecen reforzar esa conclusión. Por más que en algún caso los proyectos se muestren tímidamente atentos a los valores de los templos, como su entorno pintores$\mathrm{CO}^{50}$, o la documentación refleje un interés confeso por conservar algunas partes relevantes $^{51}$, lo cierto es que parece que ésa no fue la tónica habitual. Como hemos dicho, ni sus memorias ni sus diseños se supeditan al valor de las preexistencias, a su entorno o a sus valores asociados, y fue frecuente que los propios párrocos presentasen sus condiciones, cuando no su exigencia de corrección de determinados aspectos del proyecto.

48 AHML, Fondo Torbado, cajas 7908/3, 7913/5, $7914 / 2$ y $7914 / 4$.

49 AHML, Fondo Torbado, cajas 7912/2, 7907/3, $7914 / 3$.

${ }^{50}$ Es el caso de la citada iglesia de La Mata de Monteagudo, que intenta proyectar atendiendo a su localización entre montañas, aunque con un extravagante resultado ecléctico-historicista que desentona con el entorno (AHML, Fondo Torbado, caja 7912/2).

51 En su intervención en la iglesia de Pobladura del Valle (Zamora), en 1957, expresó que, a pesar del "interés que todos teníamos en conservar la mayor parte posible, e incluso el artesonado, no ha sido posible por el mal estado ha que ha llegado" (AHML, Fondo Torbado, caja 7907/4). En su lugar construyó con nuevas formas y materiales. 
Una de sus intervenciones más destacadas en este sentido fue la que llevó a cabo en colaboración con Luis Menéndez Pidal en la iglesia de San Tirso de Sahagún, una vez que la torre de ésta se hubo derrumbado el 29 de noviembre de 1948, horas después de que el propio Torbado fuese a comprobar su amenaza de ruina. La iglesia, considerada como una de las obras cumbre de la albañilería románica en España, experimentó entonces la reconstrucción de la torre y partes dañadas, además de la nueva construcción de otras, como el ábside meridional -“nuevo de idénticas características"-, y el pórtico que le da acceso, éste "de manera análoga" a la parte más antigua ${ }^{52}$. El resultado final condujo, más allá de los obvios condicionantes de la ruina previa, a la repristinación del monumento, con la reconstrucción de partes entonces inexistentes y la integración del conjunto en un todo donde resulta difícil discernir la novedad de cada intervención.

Torbado procedió también con nuevos añadidos en la rehabilitación del monasterio de las MMBB Carbajalas de León (1957$1959)^{53}$ y en la restauración del convento de las franciscanas clarisas descalzas de la misma ciudad. Este último, fundado en el siglo XVII, estaba a mediados del XX en muy mal estado (Fig.7) y, con motivo de la instalación en sus dependencias de la Escuela Superior de Arte Sagrado (1954), comenzaron a realizarse intervenciones de rehabilitación. Como arquitecto diocesano, Torbado proyectó diversas obras de reconstrucción en esos años, entre ellas, la de la fachada del convento en la calle Cardenal Landázuri (1962). En correspondencia con las nuevas salas interiores y la previsión de nuevos accesos, diseñó para ella nuevos vanos y varió la composición del conjunto "a fin de conseguir una mayor armonía en la fachada, la cual se reviste en su parte superior de ladrillo de la misma clase que el que tiene la parte de la iglesia, haciéndose un despiece similar para

\footnotetext{
${ }^{52}$ AHML, Fondo Torbado, caja 7911/7.

53 AHML, Fondo Torbado, cajas 7912/1 y 7913/4.
}

que resulte más entonado el conjunto" ${ }^{54}$. De esta forma, además de alterar los espacios interiores, su proyecto destruía la antigua figuración de la fachada, con sus añadidos y transformaciones históricas, para crear una nueva y artificial (transformación general de vanos -los superiores, ahora de medio punto-, inédita composición de éstos en ejes verticales, nuevo frontispicio para la portada septentrional, introducción de nuevos paramentos de ladrillo, etc.). Aunque el proyecto finalmente no se llevó a cabo, su existencia resulta igualmente ilustrativa (Fig.8). Pocos años después, las distintas ruinas que se sucedieron llevaron a la reconstrucción de casi todo el convento, incluida la fachada de Cardenal Landázuri y la de la iglesia, que fue demolida en $1971^{55}$. Las obras las dirigió el arquitecto Miguel Martín-Granizo, que tan sólo conservó, a instancias de Bellas Artes, el escudo de la Santa Cruz que lucía sobre la antigua puerta, seguramente por ser la única parte protegida al amparo del Decreto de 1963 para la conservación de escudos, emblemas y elementos históricos.

Igualmente desafortunadas fueron las intervenciones que le encomendó el obispo Luis Almarcha para el traslado y reconstrucción de edificios, obviando las recomendaciones internacionales al respecto, que proscribían desde hacía décadas este tipo de acciones por arrancar las obras del entorno que les era propio y consustancial. En 1947, a instancias del prelado, desmontó la fachada y otras partes del abandonado monasterio de San Pedro de Eslonza (Santa Olaja de Eslonza, León) para reubicarlas en la nueva iglesia de San Juan y San Pedro de Renueva (León). La intervención, bien documentada con fotografías (Fig.9-10), no estuvo igual de justificada en sus razones, criterios y procedimientos. El propio Torbado publicó un artículo al respecto en el que dejó constancia de estas carencias y

\footnotetext{
${ }^{54}$ AHML, Fondo Torbado, caja 7913/1.

55 Ma.C. PÉREZ SANTIAGO, Nuestra historia. Historia del convento de la Santa Cruz de franciscanas clarisas descalzas. León, 1605-1994, León, 1996, p. 141 y ss.
} 
de su posicionamiento ${ }^{56}$. En él, sin apenas atención al análisis y valoración del edificio original, señala que cuando se procedió al desmontaje de la fachada no restaba del monasterio más que unas cuantas ruinas: "todo lo demás se reduce a escombros de los que no se puede sacar más que el material aprovechable, que no lo es todo" 57 . Con esta referencia a lo "aprovechable" dejaba clara, pues, su visión utilitaria y su indiferencia hacia el Patrimonio arqueológico, actitud que volvía a quedar de manifiesto cuando declaraba conocer las ruinas desde hacía años, "y con mucha frecuencia he pensado en la manera de poder salvarlas, como fuese; y ya en cierta ocasión lancé la idea de utilizarlas en su lugar para la construcción de un manicomio, sin que esta idea llegase a plasmar".

Años después, de nuevo a las órdenes de Almarcha, trasladó y reconstruyó el palacio de los marqueses de Prado en Renedo de Valdetuéjar (Fig.11) con destino a la obra hospitalaria de Nuestra Señora de Regla $(1964)^{58}$. En esta ocasión el proyecto, además de la salvaje amputación del monumento original, conllevó el vaciado del entramado urbano preexistente -precisamente en las inmediaciones de la catedral, al norte de la misma, que era el único

\footnotetext{
56 También publicó un estudio sobre las fuentes públicas leonesas -J. TORBADO FRANCO, "Fuentes de León", Archivos Leoneses, no 2, 1947, pp. 101-109-, trabajo de limitada profundidad que vuelve a reflejar sus diferencias, en este caso investigadoras, con respecto a su padre.

57 J. TORBADO, "Traslado del monasterio de Eslonza", Archivos Leoneses, no 1, 1947, pp. 183-188.

58 Sobre este proyecto, véase: F.J. GONZÁLEZ, "Obra hospitalaria de N.S. de Regla", León. Casco Antiguo y Ensanche. Guía de Arquitectura, León, COAL, 2000, pp. 72-73; E. MORAIS VALLEJO, "Cuando la Restauración reinventa. La Obra Hospitalaria de Na. S ${ }^{a}$. de Regla y la calle de las Cien Doncellas de León", Arpa. Actas del Congreso Internacional "Restaurar la memoria", Diputación de Valladolid, 2003, pp. 839-849, IDEM, "Traslado de edificios históricos. El caso de León durante la etapa franquista", De Arte, no 1, 2002, pp. 113-137; E. MORAIS VALLEJO y $\mathrm{M}^{\mathrm{a}} \mathrm{D}$. CAMPOS SÁNCHEZ-BORDONA, Op. cit., pp. 237-254.
}

sector que había quedado al margen de las liberaciones, aunque ya transformado con las casas de la familia Sánchez Chicarro-, la burda utilización de los restos en un edificio y entorno nuevos, y la transformación, igualmente grave, de este último al crearse una plazoleta ante su fachada y un nuevo portillo que horadó la muralla para crear un paso hacia la carretera de los $\mathrm{Cu}$ bos. Como ha señalado Emilio Morais, el proyecto original de Torbado para el complejo hospitalario constaba originalmente de una fachada moderna muy austera, tan sólo animada por una portada tetrástila sosteniendo un balcón en la portada. Fue idea del obispo reutilizar algunas partes del palacio para la fachada, y cabe destacar que esta ocurrencia se plasmó a través de la adaptación de las piezas históricas al proyecto existente, en el sentido escenográfico que cabe entender de la operación, y con el perjuicio añadido de haber supuesto la libre disposición de sus elementos en la nueva obra, así como la alteración de las proporciones de la fachada original, que aparece ahora menos estilizada de lo que era (Fig.12). Planteamientos y consecuencias similares se verificaron también en la operación de traslado de la portada del palacio de los Quirós un par de años antes, llevada al patio delantero de la colegiata de San Isidoro por Torbado, igualmente a instancias del obispo legionense ${ }^{59}$.

\section{EL PATRIMONIO SEGÚN EL OBISPO ALMARCHA}

El activo protagonismo del obispo Luis Almarcha Hernández (1944-1970) en el Patrimonio eclesiástico de la diócesis de León, de la que Torbado era arquitecto, nos lleva a plantearnos la pertinencia de evaluar sus posiciones hacia el mismo y en materia de Restauración para entender la obra del propio Torbado.

\footnotetext{
${ }^{59}$ E. MORAIS VALLEJO y Maํ D. CAMPOS SÁNCHEZ-BORDONA, Op. cit., pp. 279-287.
} 
Hombre sumamente activo en su actividad episcopal y social, Almarcha es una de las figuras más destacadas y controvertidas del siglo XX en León y provincia. Además de su labor pastoral, escribió ensayos teológicos y sociales y promovió instituciones e iniciativas culturales, así como un sinnúmero de obras arquitectónicas y de restauración a lo largo de casi tres décadas, que coincidieron en el tiempo con las reparaciones de posguerra y otros procesos como la reestructuración de los límites diocesanos (1955-1956) o el Concilio Vaticano II.

En este último sentido, su producción raya la megalomanía: en 1960 ya contaba la construcción de 54 templos nuevos, 159 reconstruidos, 397 reparados, 131 nuevas casas rectorales y 241 reconstruidas, cifras a las que se sumaron otras muchas obras en los años siguientes ${ }^{60}$. Entre todas ellas destacan la del Seminario Menor de San Isidoro, la citada Obra Hospitalaria de Nuestra Señora de Regla, el Seminario Mayor de San Froilán, las iglesias del santuario de la Virgen del Camino, San Juan y San Pedro de Renueva (León), Jesús Divino Obrero (León) y San Claudio (León), la rehabilitación del Palacio Episcopal, o las restauraciones de las iglesias de San Miguel de Escalada y Arbas del Puerto.

En 1948 creó la Comisión Diocesana de Arte Sacro, que tenía como finalidad velar por la observancia de las normas eclesiásticas en la construcción y reparación de templos, vigilar la conservación del tesoro artístico de cada iglesia, examinar todo proyecto de imagen nueva e informar de todo lo relativo al valor artístico de los templos, imágenes, ornamentos y utensilios sa$\operatorname{cros}^{61}$. Diez años después, valiéndose de su

${ }^{60}$ L. ALMARCHA HERNÁNDEZ, Instituciones diocesanas, León, Centro de Estudios e Investigación "San Isidoro", 1970, pp. 333-338.

${ }^{61}$ Para el cumplimiento de estos cometidos la Comisión se dividió en dos secciones, una de Arquitectura, Escultura y Pintura, y otra de Artes suntuarias sagradas (L. ALMARCHA HERNÁNDEZ, p. 339) nombramiento como presidente de la Junta Nacional de Arte Sacro, organizó en León la I Semana Nacional de Arte Sacro (1958), cuyas conclusiones se recogieron en un documento -las Normas directivas de Arte Sacro (1958)- que Almarcha hizo suyas instituyéndolas como normas diocesanas el 15 de octubre de ese mismo año.

Dichas normas fueron redactadas por una comisión especial a partir de las conclusiones de las ponencias del Congreso $\mathrm{y}$, en lo que se refiere a Patrimonio y restauración arquitectónica, estuvieron especialmente determinadas por Ferrando Roig, integrante de dicho comité y ponente del seminario $^{62}$. Constituyen una carta de gran valor $\mathrm{y}$, básicamente, proponen el retorno y asunción de los postulados de la Conferencia de Atenas (1931), en los que se inspirara la Ley de Patrimonio Artístico Nacional de la II República española (1933). Así, sobre la

62 La comisión especial se constituyó con importantes delegados eclesiásticos: Agapito Fernández, Saturnino Escudero, Benedicto Nieto, José María Fernández Catón, Juan Ferrando Roig, Antonio Viñayo, José Manuel de Aguilar, el P. Hornedo y Juan Monleón. En su ponencia, Ferrando Roig propuso la Conservación como solución primera y una Restauración que se caracterizase por la competencia y humildad del arquitecto, sobria y sincera, donde cada añadido fuese pertinentemente diferenciado de las preexistencias (J. FERRANDO ROIG, "Labor orientadora de las Comisiones Diocesanas de Monumentos", I Semana nacional de arte sacro, León, 1958, pp. 35-42).

En el Congreso también intervino como ponente Íniguez Almech, a la sazón Comisario General del Patrimonio Artístico Nacional, con una interesante ponencia sobre el relativismo de los criterios teóricos en Restauración que pone en evidencia el supuesto desinterés teórico o formativo que en ocasiones se ha atribuido a este periodo, quizás de forma excesivamente determinista y generalizada (F. ÍNIGUEZ ALMECH, "Problemas que plantea la restauración de monumentos", I Semana..., pp. 77-88). La participación de Torbado en el Congreso quedó en un segundo plano. Aunque colaboró en algunas actividades, no figura entre los ponentes ni comisarios, y las actas sólo recogieron su intervención en el coloquio de la conferencia de J. Ma . de la Vega Samper sobre las tendencias de la arquitectura religiosa contemporánea, donde se abordaron temas como la "profanación de las catedrales góticas con adherencias barrocas" (I Semana, pp. 21-33). 
premisa de que los templos tienen la misión primera de servir al culto católico (art. 5), se afirma que "la restauración de monumentos antiguos viene regida hoy por un sentido de gran sobriedad y sinceridad. Ante todo consolidar y conservar lo que se pueda, sin problemáticos añadidos, sin imitaciones de estilo, sin pátinas falaces" (art. 28). Igualmente, se defendía la conservación de "todo aquello que tenga algún valor, aunque corresponda a diversas épocas" (art. 29) ${ }^{63}$.

Sin embargo, esta declaración de intenciones no siempre llegó a hacerse efectiva. En los años siguientes se llevaron a cabo intervenciones como la de Nuestra Señora de Regla (1964), que supuso la destrucción de un edificio para disponer libremente de algunos de sus despojos, o la construcción de la iglesia del santuario de la Virgen del Camino (1961), que por entonces se construía tras demoler la antigua. Y lo mismo cabría decir de algunas otras obras encomendadas a Torbado, como el citado proyecto para la fachada del convento de las franciscanas clarisas descalzas de la Santa Cruz.

A diferencia de su padre, Juan Torbado Franco mostró una distinta preocupación y sensibilidad hacia el Patrimonio. Esta diferencia seguramente esté motivada por su distinta formación y contexto restaurador, los del segundo caracterizados por la pérdida de peso de la Historia y los cambios verificados en España tras la Guerra Civil, con lo que supusieron para la Teoría de la Restauración y los paradigmas hasta entonces admitidos. Sin embargo, más allá de la mengua generalizada de pulso en el debate teórico -generalizada, aunque no ausente-, creemos que existen otras variables de índole personal. Torbado Franco no heredó la misma pasión por los monumentos, ni la iniciativa, ni la valentía de su progenitor.

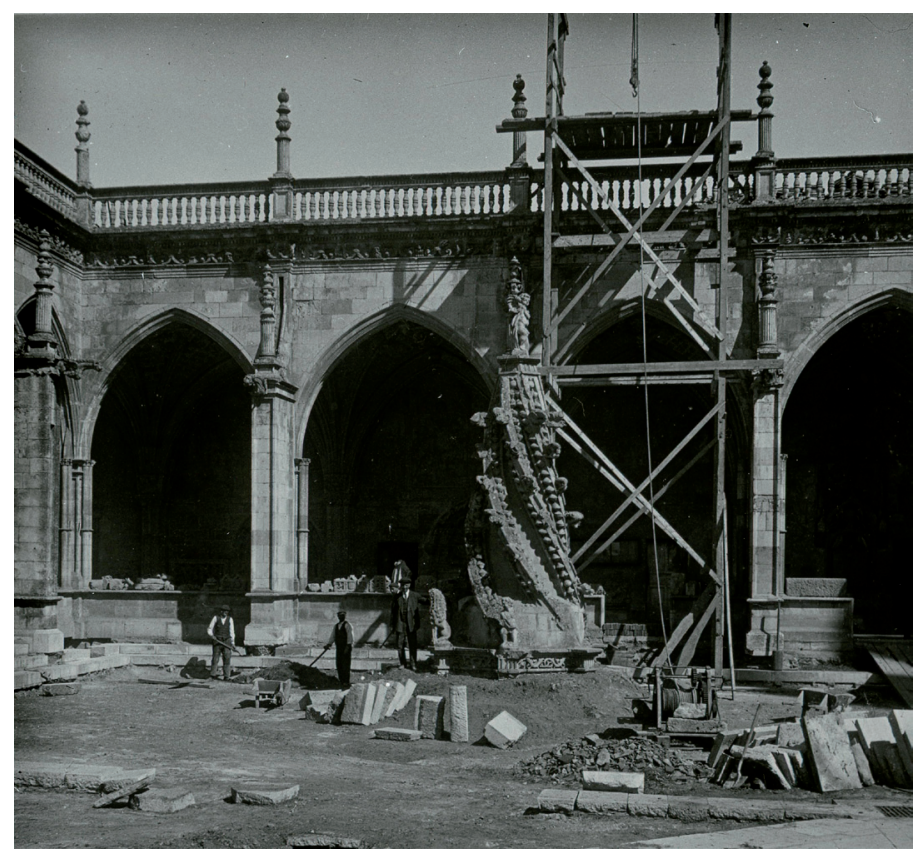

- Fig.1. Pavimentación del Claustro de la Catedral de León (J.C. Torbado, 1927). UVa, Fondo Torbado, 1-5.

\footnotetext{
${ }^{63}$ I Semana..., pp. 113-118; J. Mª FERNÁNDEZ CATÓN, El Patrimonio cultural de la Iglesia en España y los acuerdos entre el Estado español y la Santa Sede, León, 1980, p. 71 y ss.
} 


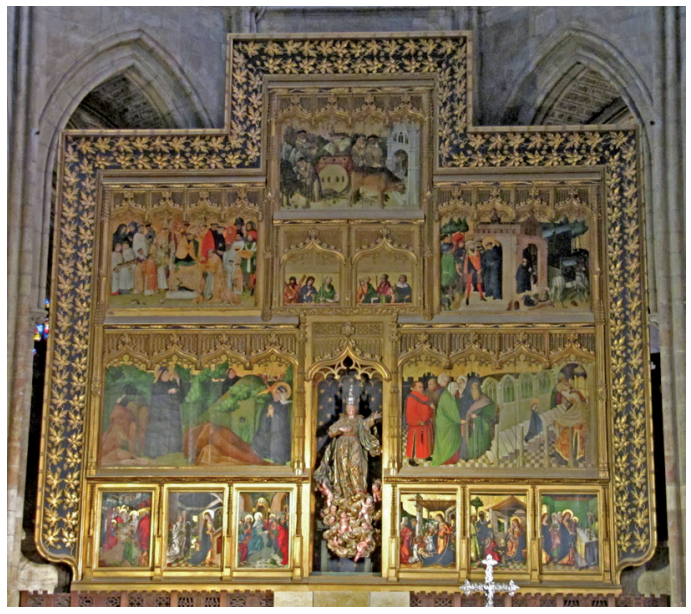

- Fig.2. Catedral de León. Retablo de Nicolás Francés, recompuesto por J.B. Lázaro y J.C. Torbado (1900-1907).

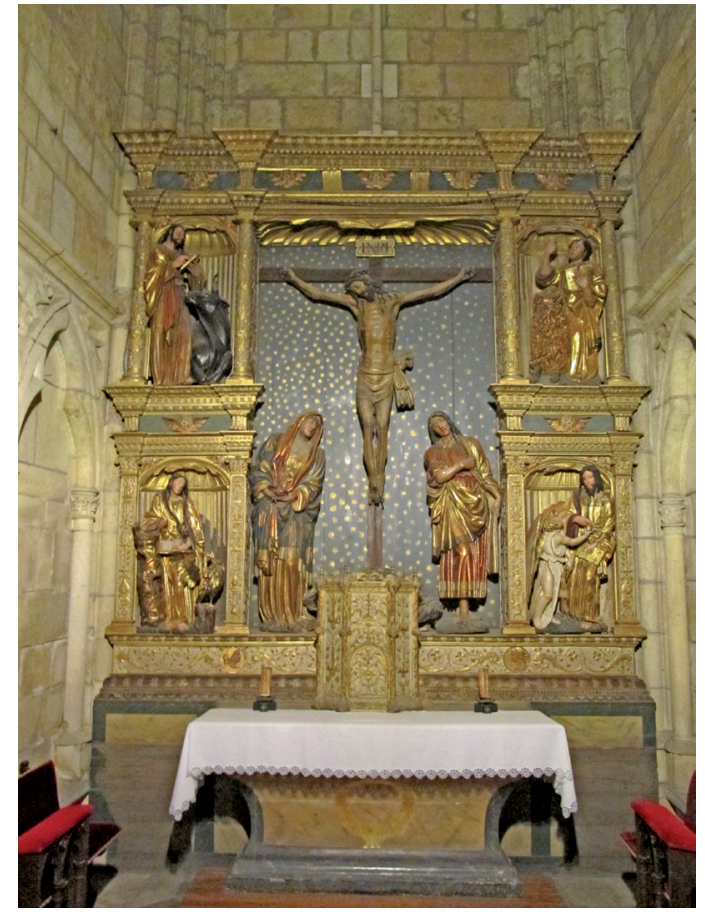

- Fig.3. Catedral de León. Retablo de la capilla del Cristo, recompuesto por J.C. Torbado (1931).

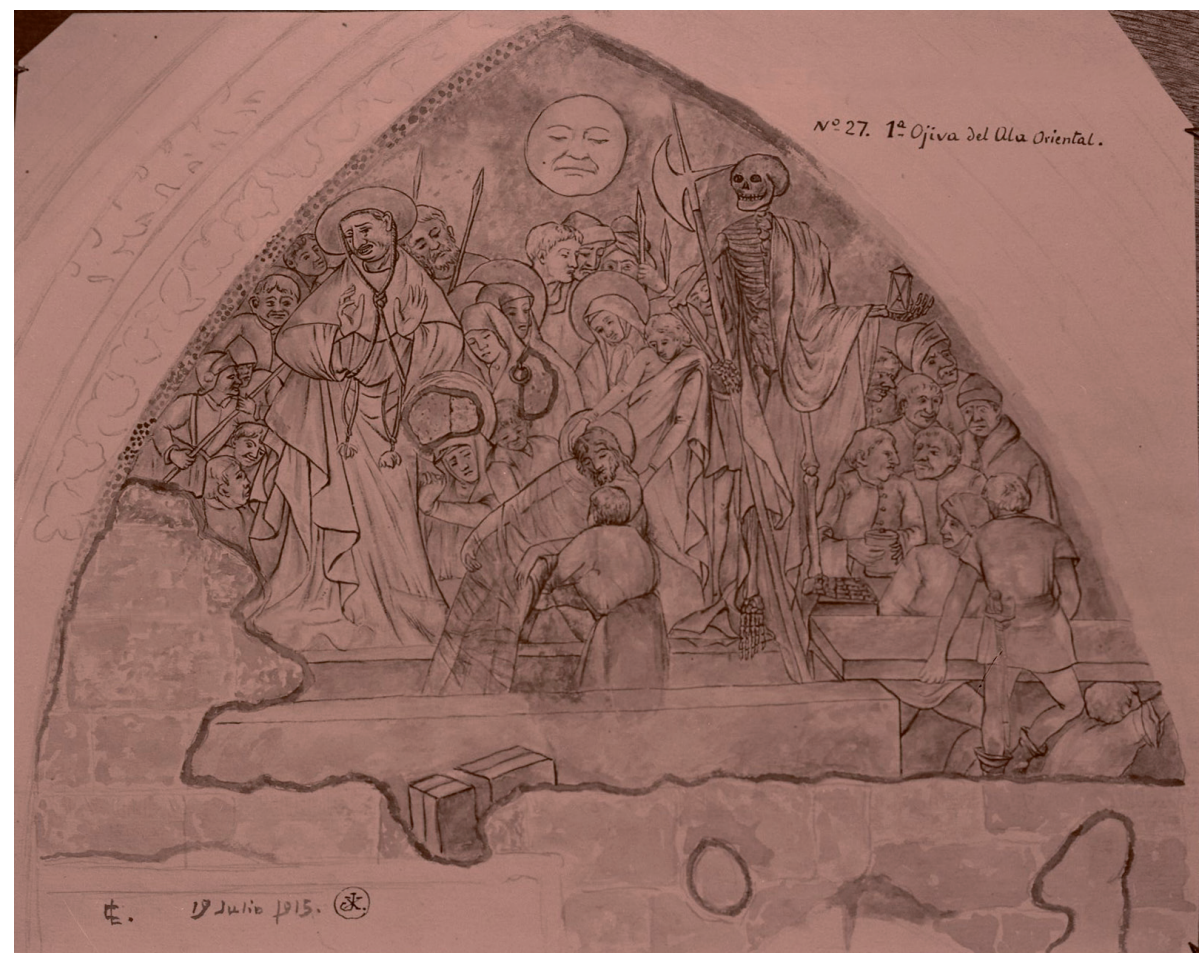

- Fig.4. Pinturas del claustro de la Catedral de León: “1ª ojiva del ala oriental” (J.C. Torbado, julio de 1915). UVa, Fondo Torbado, 277-3344. 


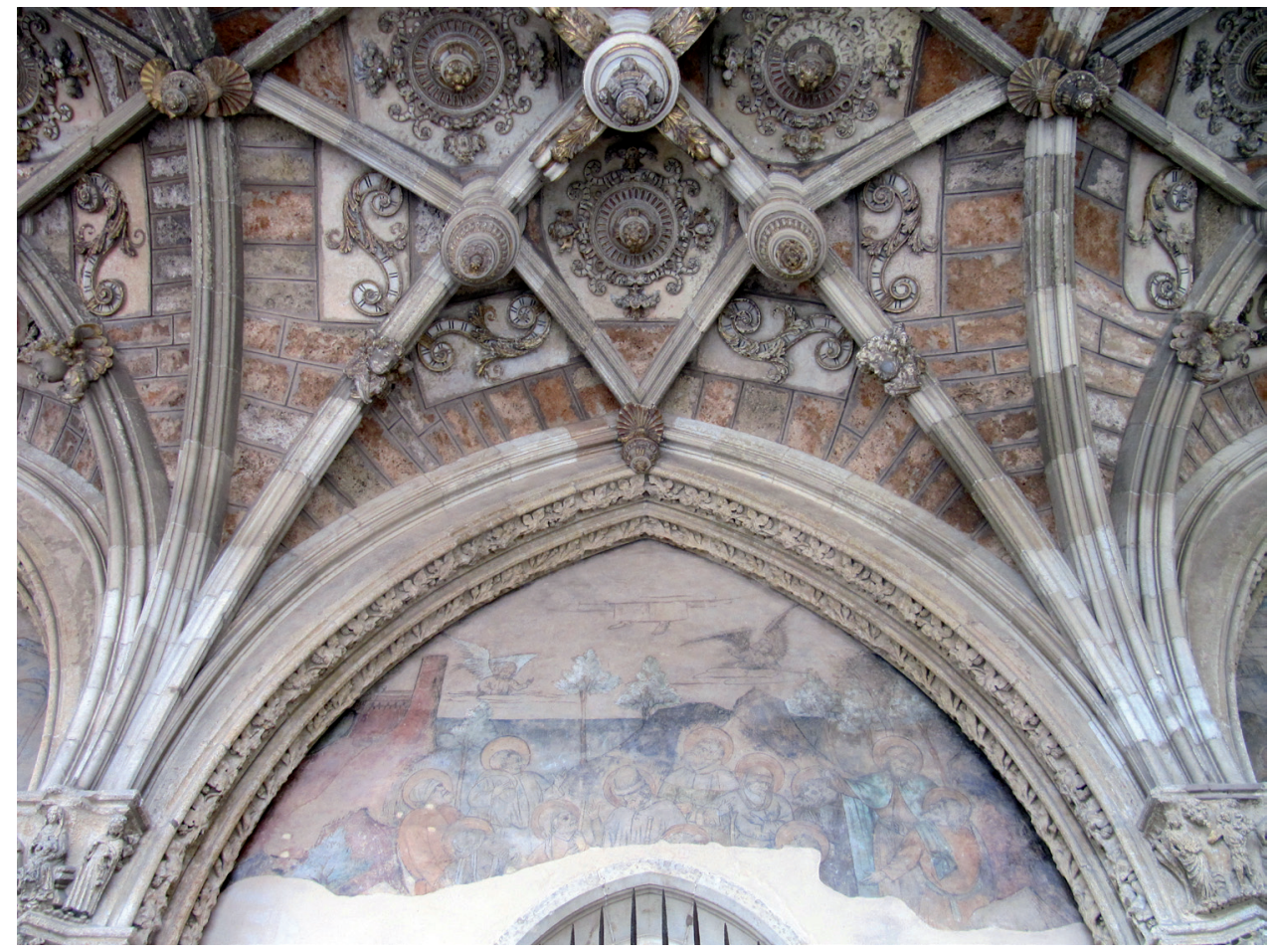

- Fig.5. Catedral de León, bóvedas y pinturas de la crujía meridional del claustro.

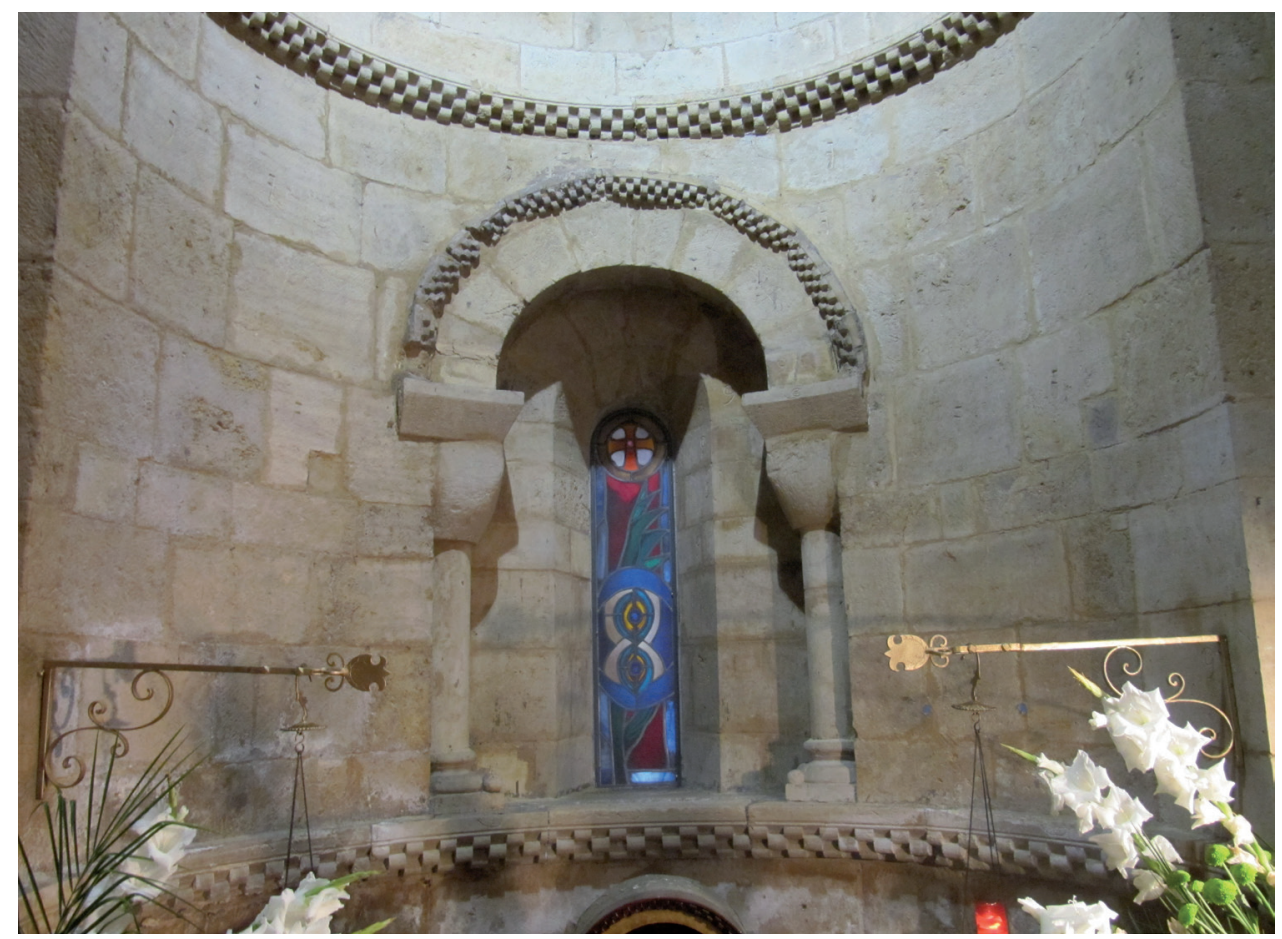

- Fig.6. Ábside de la iglesia de Santa María del Mercado (León), restaurado por J.C. Torbado. 


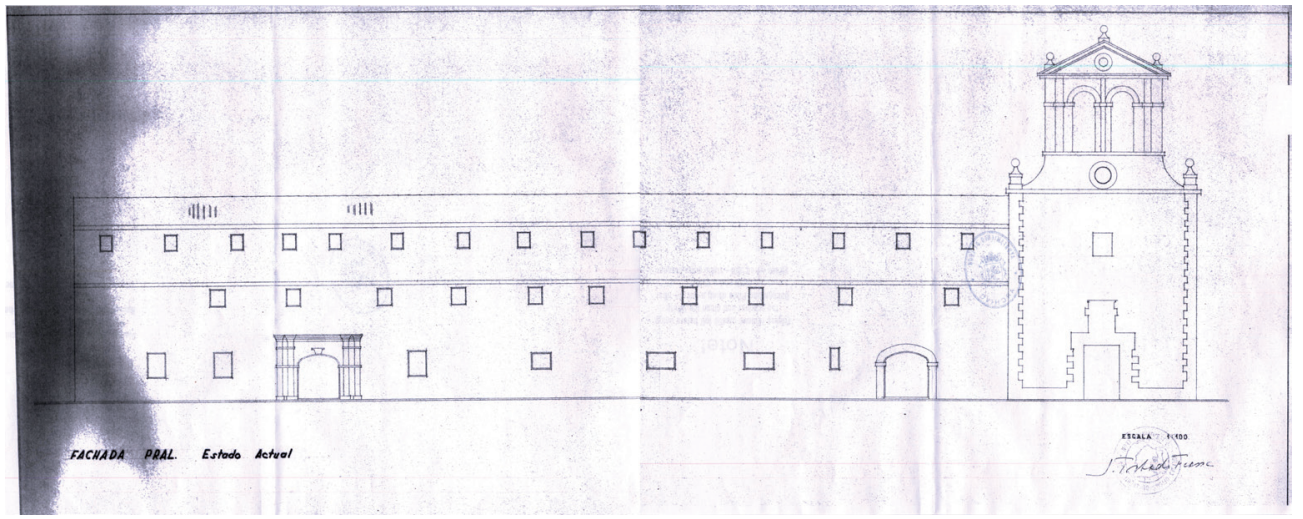

- Fig.7. Proyecto para la fachada del convento de las RRMM franciscanas descalzas (León). Estado previo. J. Torbado Franco, 1962 (AML, Torbado, 7913-1).

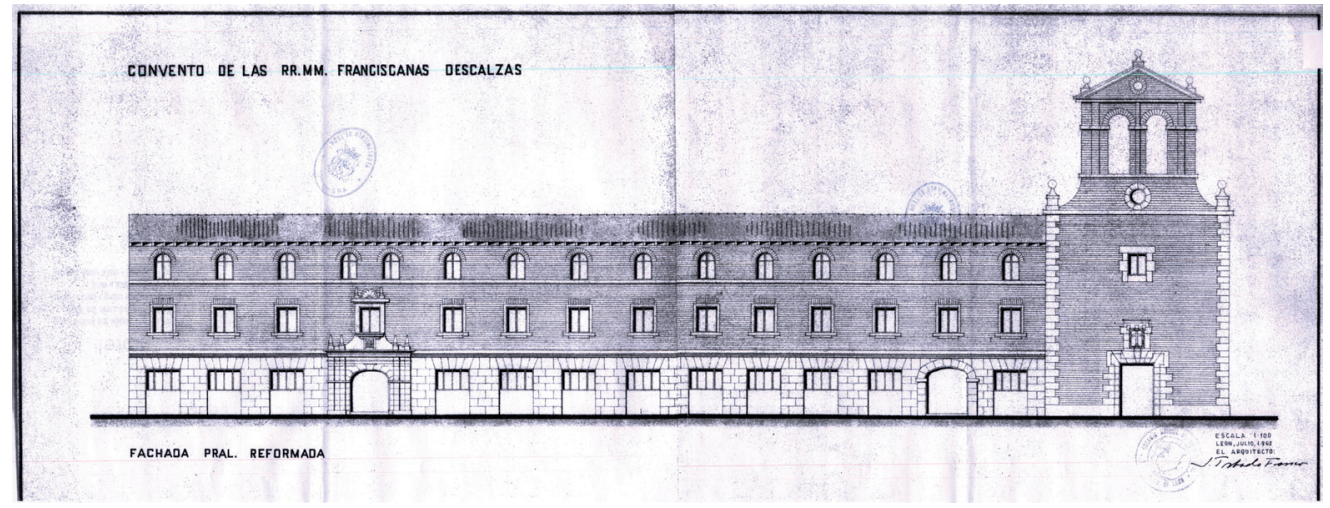

- Fig.8. Proyecto para la fachada del convento de las RRMM franciscanas descalzas (León). Reforma. J. Torbado Franco, 1962 (AML, Torbado, 7913-1).

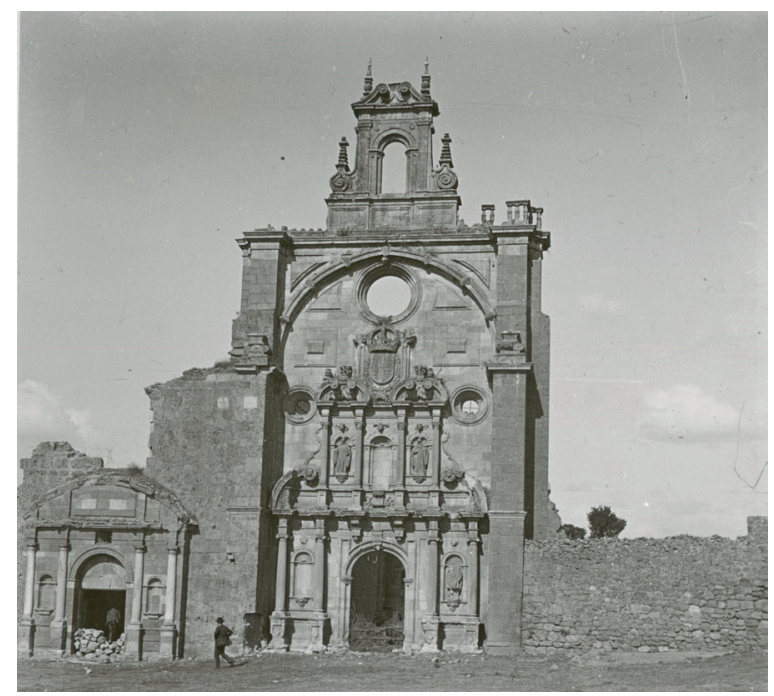

- Fig.9. Monasterio de San Pedro de Eslonza (Santa Olaja de Eslonza, León), s/f. Uva, Fondo Torbado, 67-777. 


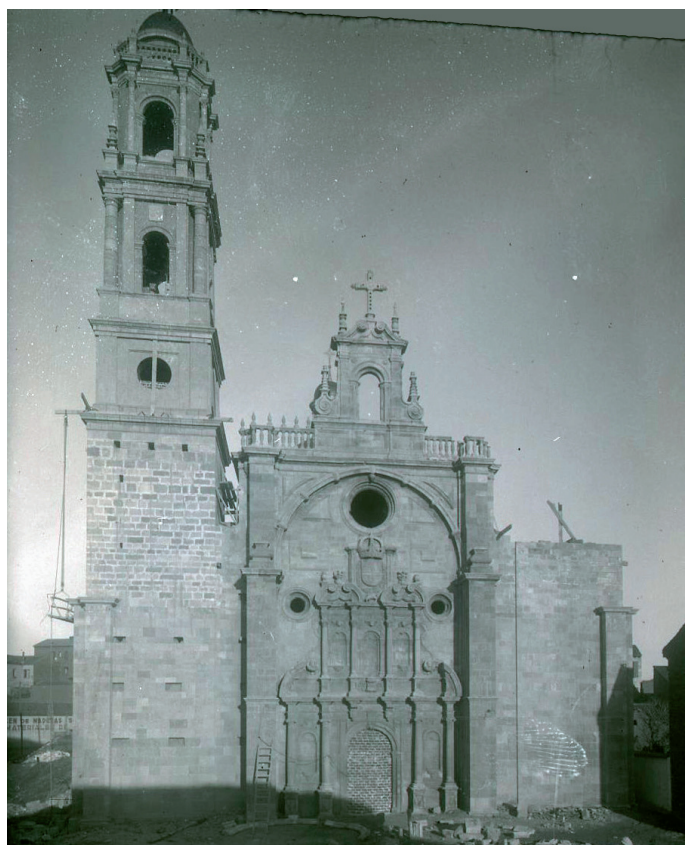

- Fig.10. Iglesia de San Juan y San Pedro de Renueva (León), obras con la fachada de San Pedro de Eslonza (J. Torbado Franco, 1947-1953). UVa, Fondo Torbado, 263-3126.

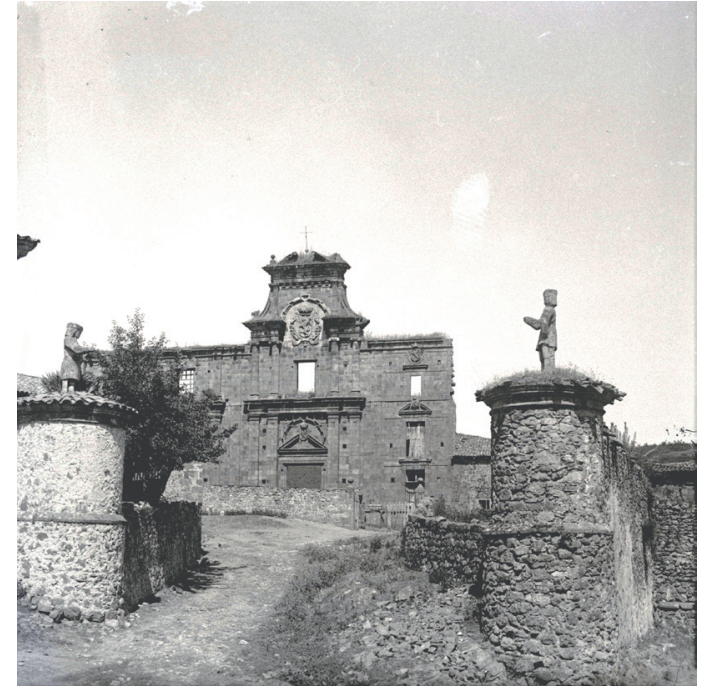

- Fig.11. Palacio de los marqueses de Prado (Renedo de Valdetuéjar, León), julio de 1928. Uva, Fondo Torbado, 207-2523.

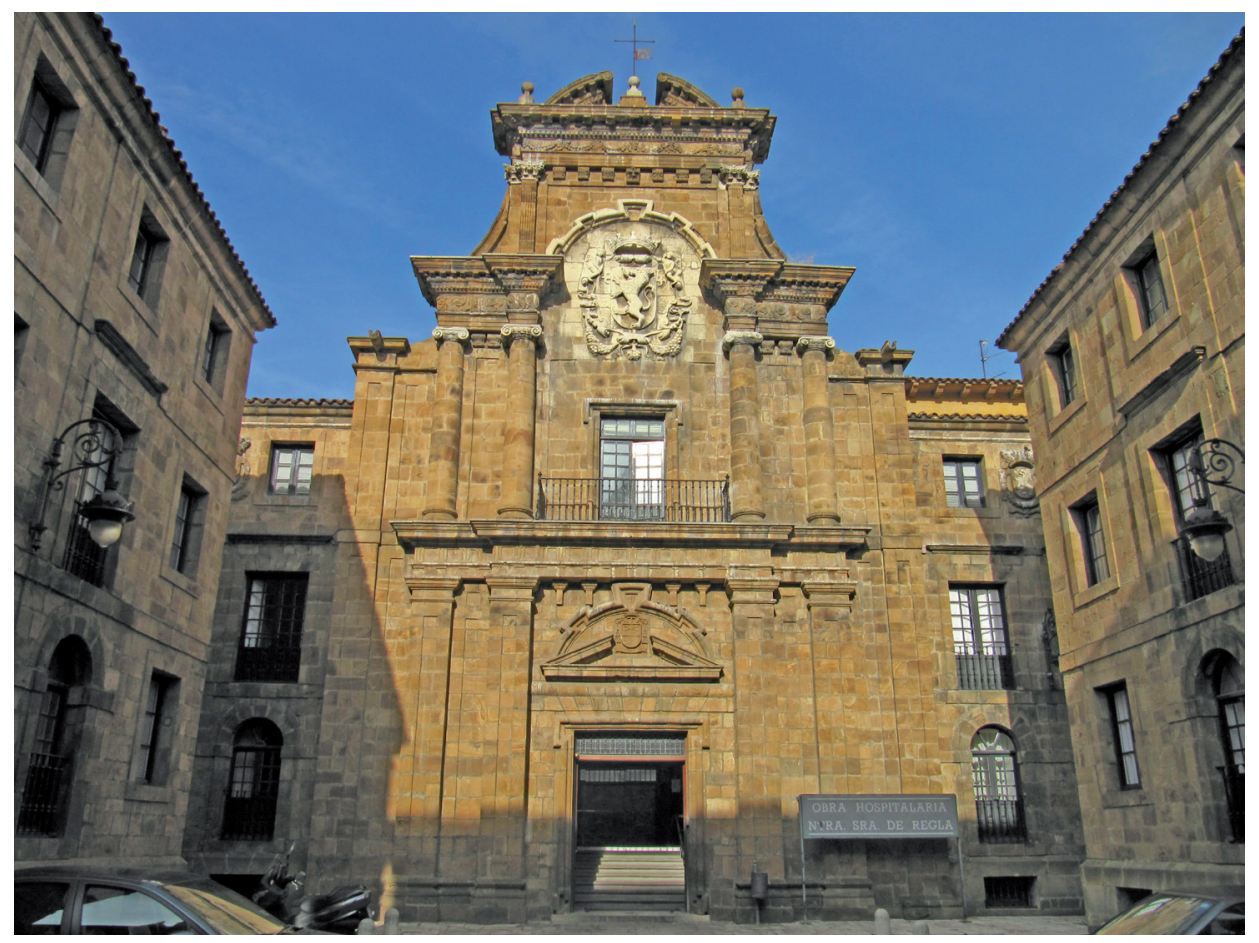

- Fig.12. Obra hospitalaria de Nra. Sra. de Regla (León), con la fachada del palacio de Renedo de Valdetuéjar. J. Torbado Franco (1964). 